\title{
Magnetron sputtered TiN thin films toward enhanced performance supercapacitor electrodes
}

\author{
Binbin Wei ${ }^{1} \cdot$ Hanfeng Liang ${ }^{2} \cdot$ Dongfang Zhang ${ }^{1} \cdot$ Zhengbing $\mathbf{i}^{3} \cdot$ Hao Shen ${ }^{1} \cdot$ Zhoucheng Wang $^{1}$
}

Received: 10 January 2018 / Accepted: 28 March 2018 / Published online: 9 April 2018

(c) The Author(s) 2018

\begin{abstract}
Supercapacitors as a new type of energy storage devices bridging the gap between conventional capacitors and batteries have aroused widespread concern. Herein, binder-free titanium nitride (TiN) thin film electrodes for supercapacitors prepared by reactive magnetron sputtering technology are reported. The effect of $\mathrm{N}_{2}$ content on the supercapacitor performance is evaluated. A highest specific capacitance of $27.3 \mathrm{mF} \mathrm{cm}{ }^{-2}$ at a current density of $1.0 \mathrm{~mA} \mathrm{~cm}{ }^{-2}$, together with excellent cycling performance ( $98.2 \%$ capacitance retention after 20,000 cycles at $2.0 \mathrm{~mA} \mathrm{~cm}{ }^{-2}$ ) is achieved in a $0.5 \mathrm{M} \mathrm{H}_{2} \mathrm{SO}_{4}$ aqueous electrolyte. More importantly, a symmetric supercapacitor device assembled on the basis of TiN thin films can deliver a maximum energy density of $17.6 \mathrm{mWh} \mathrm{cm}^{-3}$ at a current density of $0.2 \mathrm{~mA} \mathrm{~cm}^{-2}$ and a maximum power density of $10.8 \mathrm{~W} \mathrm{~cm}^{-3}$ at a current density of $2 \mathrm{~mA} \mathrm{~cm}^{-2}$ with remarkable cycling stability. As a consequence, TiN thin films demonstrate great potential as promising supercapacitor electrode materials.
\end{abstract}

Keywords Supercapacitor $\cdot$ Energy storage $\cdot$ Titanium nitride $\cdot$ Magnetron sputtering

\section{Introduction}

Energy security has become a key factor that restricts the sustainable development of human civilization, triggering tremendous efforts to develop renewable and non-polluting new energy $[1,2]$. Among energy storage systems, supercapacitors have been considered to have potential applications in portable electronics and hybrid electric vehicles due to fast charge/discharge rate, long-term cycle stability, excellent rate capability, high-power density, and low cost

Electronic supplementary material The online version of this article (https://doi.org/10.1007/s40243-018-0117-9) contains supplementary material, which is available to authorized users.

Hanfeng Liang

hanfeng.liang@kaust.edu.sa

$\triangle$ Zhoucheng Wang

zcwang@xmu.edu.cn

1 College of Chemistry and Chemical Engineering, Xiamen University, Xiamen 361005, China

2 Materials Science and Engineering, King Abdullah University of Science and Technology (KAUST), Thuwal 23955, Saudi Arabia

3 School of Materials Science and Engineering, Xiamen University of Technology, Xiamen 361024, China
[3-5]. Significantly, supercapacitors can provide higher power densities than conventional capacitors, and they also possess energy densities much higher than those of batteries $[5,6]$. As previously reported, carbon-based materials and transition metal oxides widely used in supercapacitors possess their own advantages and shortcomings. Although electrical double-layer capacitors (EDLCs) based on carbonbased materials can achieve high-power density and cycling stability, the relatively low energy density due to low-specific capacitance restricts widespread application [7, 8]. In contrast, pseudocapacitors using transition metal oxides can deliver higher energy density than that of EDLCs, however, suffer from poor cyclic stability and low power density [9]. Recently, transition metal nitrides have become a research hotspot on account of excellent chemical and thermal stability, superior electrical conductivity and outstanding electrochemical property $[10,11]$. Especially, titanium nitride (TiN) as one of important metal nitrides has aroused particular attention because of its electric conductivity close to that of metals (4000-55,500 S cm${ }^{-1}$ ) [12]. Sun et al. designed the TiN@C nanotube-based fiber electrodes by one-step nitridation and complete carbon coating process, and a specific capacitance of $19.4 \mathrm{mF} \mathrm{cm}^{-2}$ at a scan rate of $10 \mathrm{mV} \mathrm{s}^{-1}$ was achieved [13]. Tian et al. prepared titanium nitride nanotube array by a simple adsorption-reduction process and it 
showed a specific capacitance of $25.2 \mathrm{mF} \mathrm{cm}^{-2}$ at a scan rate of $100 \mathrm{mV} \mathrm{s}^{-1}$ [14]. However, they have the following drawbacks: (1) involvement of toxic gas $\left(\mathrm{NH}_{3}\right)$ and high temperature, (2) difficulty to control the oxygen amount and (3) usage of binder and conductive additives. To avoid these problems, directly depositing the active materials onto the substrate has been proposed. Achour et al. demonstrated the TiN thin film electrodes sputtered with a highest specific capacitance of $8.8 \mathrm{mF} \mathrm{cm}^{-2}$ at a scan rate of $100 \mathrm{mV} \mathrm{s}^{-1}$ [15]. Currently, a major challenge of using TiN thin films as supercapacitor electrodes is to further improve their specific capacitance. To the end, we design the TiN thin films with varying degrees of porosity by adjusting the nitrogen gas flow rate. Among them, the TiN thin film electrode with $9 \% \mathrm{~N}_{2}$ content is found to exhibit a significantly enhanced specific capacitance of $27.3 \mathrm{mF} \mathrm{cm} \mathrm{cm}^{-2}$ at a current density of $1.0 \mathrm{~mA} \mathrm{~cm}^{-2}\left(42.6 \mathrm{mF} \mathrm{cm}^{-2}\right.$ at $\left.100 \mathrm{mV} \mathrm{s}^{-1}\right)$ along with outstanding cycling performance. Significantly, we have successfully demonstrated a symmetric supercapacitor device using two identical TiN thin films that reaches an impressive energy density of $17.6 \mathrm{mWh} \mathrm{cm}^{-3}$ at a power density of $1.1 \mathrm{~W} \mathrm{~cm}^{-3}$.

\section{Experimental details}

\section{Growth of TiN thin films}

TiN thin films were produced on single polished silicon (100) wafers using a reactive magnetron sputtering system for $30 \mathrm{~min}$. The cylindrical Ti metallic target $(99.995 \%$ purity) with a diameter of $76 \mathrm{~mm}$ and a thickness of $5 \mathrm{~mm}$ was used for deposition. Prior to the sputtering process, the Si substrates were subjected to ultrasonic cleaning successively in acetone and ethanol for $15 \mathrm{~min}$, respectively. The detailed deposition parameters had been shown in our previous work [16]. The difference was that the total deposition pressure kept invariable $(2.0 \mathrm{~Pa})$ and the nitrogen gas $\left(\mathrm{N}_{2}\right.$, $99.999 \%$ ) flow rate varied from 3 to $15 \%$ of the total gas flow rate with increments of three, accompanied by a simultaneous change in argon gas (Ar, 99.999\%) flow rate. The sample identification and deposition conditions for TiN thin films are listed in Table 1.

\section{Characterization}

X-ray diffraction (XRD, Philips X'pert PRO) was taken to analyse the crystal structure and phase formation using $\mathrm{Cu} \mathrm{K}_{\alpha}$ radiation. Raman spectroscopy was acquired by an XploRA Raman at $532 \mathrm{~nm}$ excitation wavelength. X-ray photoelectron spectroscopy (XPS, PHI-Quantum 2000) was carried out with $\mathrm{Al} \mathrm{K}_{\alpha}$ radiation to study the chemical states and compositions of TiN thin films. The morphologies and
Table 1 Summary of sample identification and deposition conditions for TiN thin films

\begin{tabular}{lrrrrr}
\hline Sample ID & TiN3 & TiN6 & TiN9 & TiN12 & TiN15 \\
\hline Deposition pressure (Pa) & 2.0 & 2.0 & 2.0 & 2.0 & 2.0 \\
$\mathrm{~N}_{2}$ flow rate (sccm) & 1.8 & 3.6 & 5.4 & 7.2 & 9.0 \\
Ar flow rate (sccm) & 58.2 & 56.4 & 54.6 & 52.8 & 51.0 \\
\hline
\end{tabular}

microstructures of TiN thin films were observed by scanning electron microscopy (SEM, ZEISS Sigma) and transmission electron microscopy (TEM, Tecnai F30), respectively. The surface roughnesses of TiN thin films were determined using tapping-mode atomic force microscopy (AFM, Agilent 5500).

\section{Electrochemical measurements}

Cyclic voltammetry (CV), galvanostatic charge-discharge (GCD), and electrochemical impedance spectroscopy (EIS) were performed on a $\mathrm{CHI} 660 \mathrm{E}$ electrochemical workstation. Owing to excellent electronic conductivity, the deposited TiN thin films can directly be used as working electrode and as current collector without further process steps. For single electrode, the electrochemical performance was investigated in a $0.5 \mathrm{M} \mathrm{H}_{2} \mathrm{SO}_{4}$ aqueous electrolyte within a three-electrode cell system where TiN thin films, $\mathrm{Ag} / \mathrm{AgCl}$ and $\mathrm{Pt}$ wire were served as the working electrode, reference electrode and counter electrode, respectively. Whereas in the symmetric supercapacitor device, two identical pieces of TiN thin films were sandwiched by Celgard 3501 in a $0.5 \mathrm{M} \mathrm{H}_{2} \mathrm{SO}_{4}$ aqueous electrolyte.

\section{Results and discussion}

To identify the phase formation of as-deposited thin films, XRD was carried out. Comparison of XRD patterns for TiN thin films is depicted in Fig. 1a. All the diffraction peaks match well with those of the fcc TiN (JCPDS card no. 87-0628) [17]. No other impurity diffraction peak is detected, indicating that as-prepared thin films are just composed of TiN. Moreover, it can be speculated from the (111) planes that the grain size firstly increases and then decreases based on Scherrer formula [18], which will be further corroborated. Raman spectroscopy is another effective technique to determine the crystal structure, as shown in Fig. 1b. The characteristic peaks centered at $\sim 210,320$ and $520-590 \mathrm{~cm}^{-1}$ are assigned to TiN Raman scattering, induced by acoustical phonons and optical phonons, respectively, thereby further confirming the formation of TiN phase $[19,20]$. Information on the chemical bonding states of TiN thin films were examined by XPS characterization. The Ti2p 

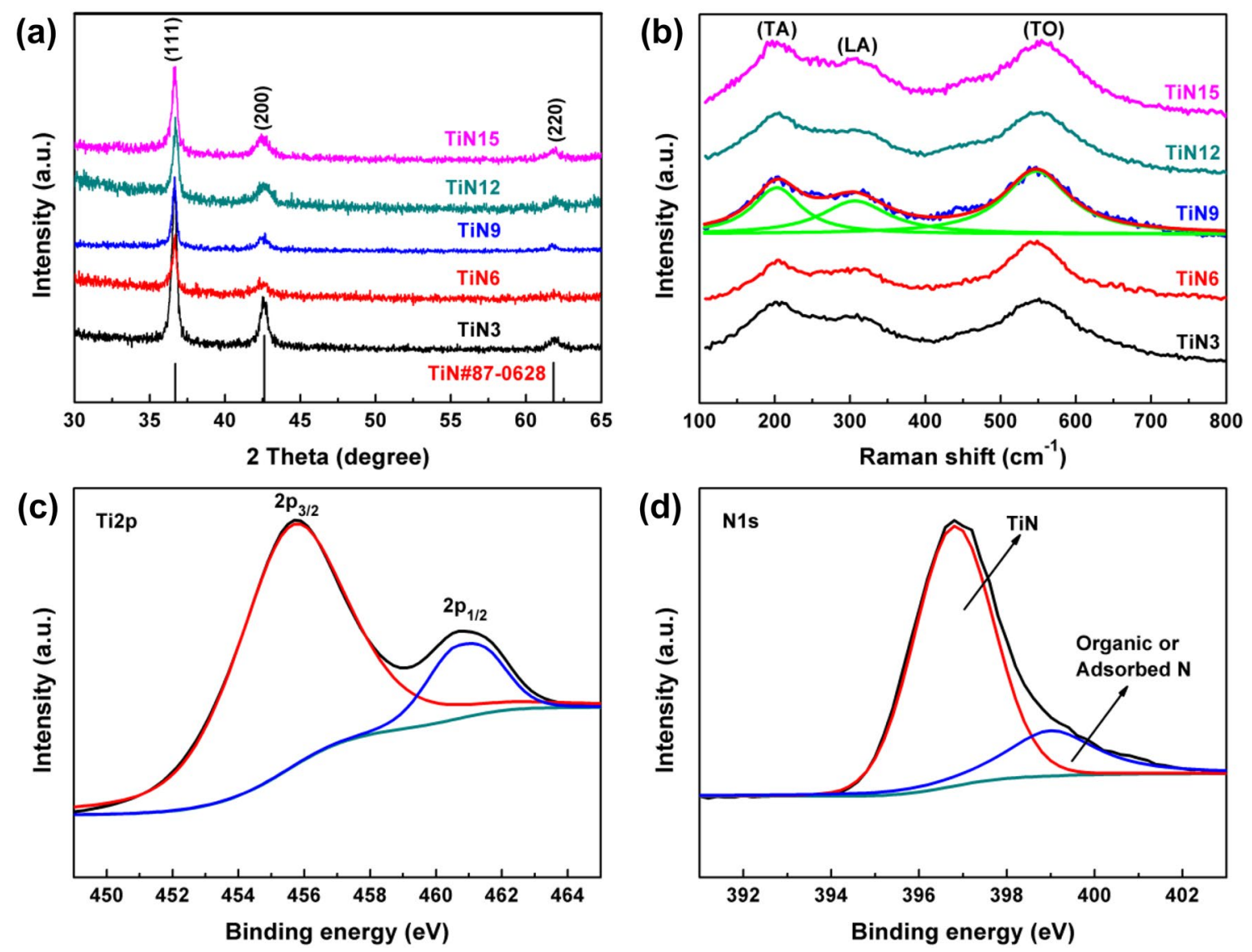

Fig. 1 a XRD patterns, b Raman spectra, Core-level c Ti2p and d N1 s XPS spectra collected for TiN thin films

and N1 s XPS spectra of a representative thin film (TiN9) are presented in Fig. 1c, d. In the Ti2p spectra, the peaks located at about 455.6 and $460.9 \mathrm{eV}$ correspond to Ti2 $\mathrm{p}_{3 / 2}$ and Ti2 $\mathrm{p}_{1 / 2}$ components of TiN, respectively [21]. The N1 s spectra is deconvoluted into two peaks with binding energies of 396.7 and $399.0 \mathrm{eV}$ that are indexed to TiN and organic or adsorbed N, respectively [22, 23].

Figure 2a describes schematically the synthetic route of TiN thin films grown on the Si substrates prepared by reactive magnetron sputtering. Different nitrogen gas flow rates are poured into the sputtering chamber to obtain different surface roughness levels and electronic conductivities. The surface SEM images of TiN thin films are shown in Fig. 2b-f. It can be observed that these films exhibit a granular surface morphology. In addition, the average granule size firstly ascends and then descends, which coincides with the trend mentioned in the XRD result. The crosssectional microstructures of TiN thin films imaged by SEM (Fig. 2g-k) displays growth morphology containing columnar microstructure that is consistent with the characterization of Zone T structure [24]. As the nitrogen content increases, the film thicknesses show a slight decrease, however, and keep the same order of magnitude (670-780 nm) mainly due to the fact that a nitrided compound layer having a lower sputtering rate than metals will form on the target surface [25]. As shown in Fig. S1, the clear lattice fringe of $0.24 \mathrm{~nm}$ is observed, which can be ascribed to the (111) plane of the cubic TiN, and the selected area electron diffraction (SAED) shows polycrystalline nature of TiN.

The three-dimensional surface topographies of TiN thin films deposited under different $\mathrm{N}_{2}$ content were estimated by AFM. Figure 3 displays the variation of root mean square surface roughness $\left(R_{a}\right)$ against $\mathrm{N}_{2}$ content. It is clear that the $R_{a}$ increases firstly from 2.205 to $3.362 \mathrm{~nm}$, then decreases back to $2.553 \mathrm{~nm}$. This result can be explained as follows. With the increase of the nitrogen content, the collisions between the sputtered ions will become frequent so that the sputtered ions with reduced momentum are scattered around on the surface of substrates, ensuring enough time for the nucleus to grow [26]. At higher nitrogen content, the increase in the number of ions facilitates the secondary sputtering of titanium atoms that have sputtered onto the surface of the substrate in the vacuum chamber, thus causing a decrease in roughness [27].

To investigate the effect of $\mathrm{N}_{2}$ content on the electrochemical properties of TiN thin films as supercapacitor electrodes, 


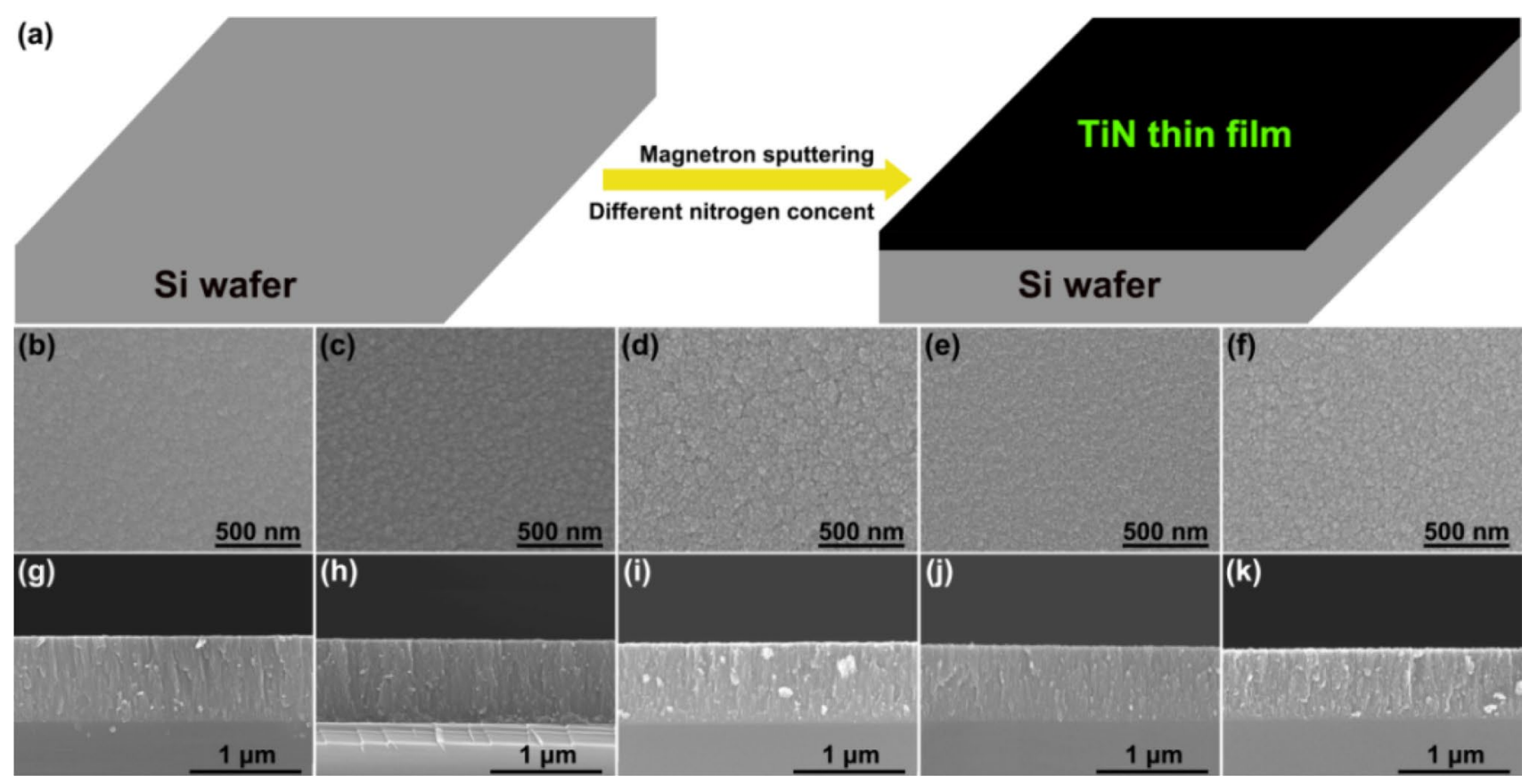

Fig. 2 a Schematic illustration of the fabrication process, $\mathbf{b}-\mathbf{f}$ Surface morphologies and $\mathbf{g}-\mathbf{k}$ Cross-sectional microstructures of TiN thin films

(a)

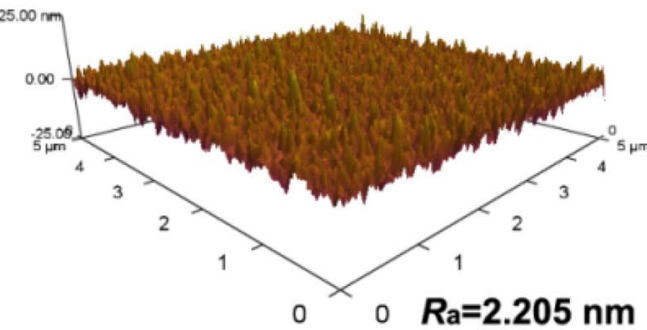

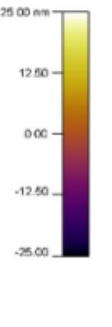

(b)

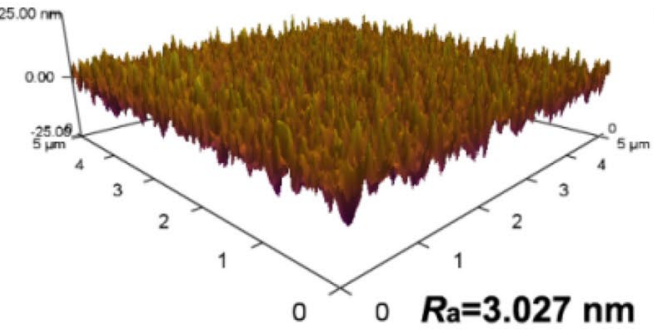

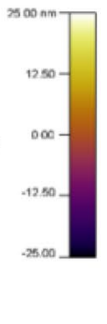

(c)

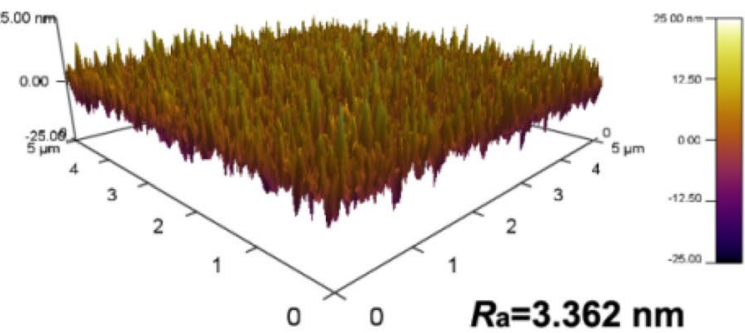

(d)

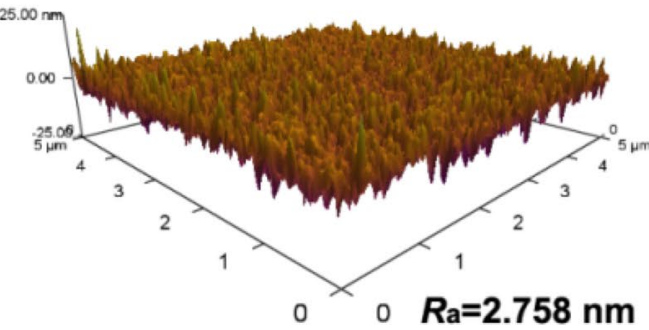

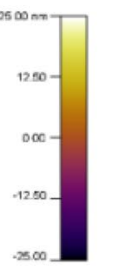

(e)

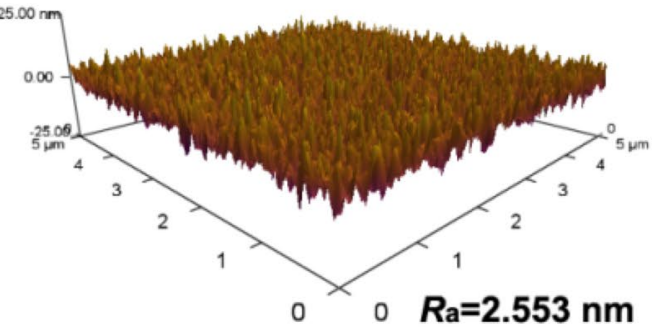

Fig. 3 Three-dimensional AFM images for TiN thin films deposited under different $\mathrm{N}_{2}$ content at $5 \mu \mathrm{m} \times 5 \mu \mathrm{m}$ scan size 
all the electrochemical measurements were carried out using a three-electrode setup in $0.5 \mathrm{M} \mathrm{H}_{2} \mathrm{SO}_{4}$ aqueous electrolyte. Figure $4 \mathrm{a}$ shows the $\mathrm{CV}$ curves of TiN thin films deposited under different $\mathrm{N}_{2}$ content with a stable potential window of $0-0.8 \mathrm{~V}$. It is noticed that these CV profiles are box-like in shapes, suggesting that TiN thin film electrodes can operate at $0.8-0 \mathrm{~V}$. In comparison to other thin films, a higher current density response and larger enclosed CV area are obtained for the TiN9 thin film electrode. GCD curves of different TiN thin films at a current density of $1.0 \mathrm{~mA} \mathrm{~cm}^{-2}$ are plotted in Fig. 4b. The time-potential curves are a little nonlinear with good symmetry, indicating a capacitance characteristic of both pseudocapacitance and electric double-layer capacitance [28]. An equilibrium reaction, such as $\mathrm{TiN}+\mathrm{H}^{+} \leftrightarrow \mathrm{TiN} \| \mathrm{H}^{+}+\mathrm{TiN}-\mathrm{H}^{+}$, could occur on the electrode surface $\left(\mathrm{TiN}^{+} \mathrm{H}^{+}\right.$represents the double-layer capacitance and $\mathrm{TiN}-\mathrm{H}^{+}$represents the pseudocapacitance that originates from the chemisorption of protons). Additionally, it can be obviously seen that the TiN9 thin film electrode presents the longest discharge time among five samples, implying a certain extent of enhancement in specific capacitance. It should be specially pointed out here that the poor charge-discharge characteristic of the TiN3 thin film electrode relates to its good crystallinity [29], which is in accordance with the XRD observations. The specific capacitances with respect to $\mathrm{N}_{2}$ content calculated from the discharge curves are revealed in Table S1 and the final results are displayed in Fig. 4c. The TiN9 thin film electrode yields a higher specific capacitance of $27.3 \mathrm{mF} \mathrm{cm} \mathrm{cm}^{-2}$ than those of other thin films at the same current density. The better electrochemical performance is attributed to three aspects: firstly, the higher specific area is beneficial to the contact between active materials and electrolyte, and thus promotes faster adsorption/desorption of ions (Fig. 3) [30]; secondly, the absence of binder can improve the electrical conductivity and facilitate electron transport [31]; thirdly, the higher electric conductivity decreases the electrode polarization and the internal resistance (Table S2) [32].
To further advance the understanding of electrochemical properties of TiN thin film electrodes, CV, GCD and EIS measurements are conducted on the TiN9 thin film electrode with optimal electrochemical performance. Figure 5a illustrates the CV curves of the TiN9 thin film electrode at various sweeping rates from 50 to $1000 \mathrm{mV} \mathrm{s}^{-1}$. As the scan rate is increased, no significant deviations are observed from the CV shape, showing good electrochemical reversibility and excellent capacitive behavior. The effect of current density on the GCD response for the TiN9 thin film electrode is displayed in Fig. 5b. The negligible IR drop found from the discharge curve reveals a low internal resistance [33]. Figure $5 \mathrm{c}$ shows the dependence of specific capacitance for the TiN9 thin film electrode on the current density (for details of calculation, see Table S3). The specific capacitances of the TiN9 thin film electrode are 34.6, 29.6, 27.3 and $21.6 \mathrm{mF} \mathrm{cm}^{-2}$ at the current densities of $0.2,0.5,1.0$ and $2.0 \mathrm{~mA} \mathrm{~cm}^{-2}$, which is much higher than the values reported for TiN nano film $\left(1.53 \mathrm{mF} \mathrm{cm}^{-2}\right.$ at $\left.3.5 \mu \mathrm{A} \mathrm{cm}^{-2}\right)$ [34] and $\mathrm{CrN}$ thin film $\left(12.8 \mathrm{mF} \mathrm{cm}^{-2}\right.$ at $\left.1.0 \mathrm{~mA} \mathrm{~cm}^{-2}\right)$ [16] (also see Table S4). With the current density increases, a drop in the specific capacitance occurs because of the limited utilization of active materials at high current density [35]. It is worth noting that $62.4 \%$ capacitance retention is maintained even at higher current density of $2.0 \mathrm{~mA} \mathrm{~cm}{ }^{-2}$, indicative of good rate performance. Figure $5 \mathrm{~d}$ displays the cycling performance of the TiN9 thin film electrode evaluated by at $2.0 \mathrm{~mA} \mathrm{~cm}{ }^{-2}$ over 20,000 cycles. Only $1.8 \%$ capacitance loss is observed after 20,000 cycles, demonstrating outstanding cycling performance, which outweighs those of most metal nitrides ever published, such as $\mathrm{MoN}_{\mathrm{x}} / \mathrm{TiN}$ NTA $(93.8 \%$ after 1000 cycles) [36] and TiN@C nanotube (78\% after 10,000 cycles) [13].

EIS analysis is an effective tool to examine the interfacial property of thin film electrodes. As shown in Fig. 5e, the Nyquist plot consists of a semicircle and a straight line at the high and low frequency region, respectively. The small diameter semicircle indicates low charge-transfer resistance (a)

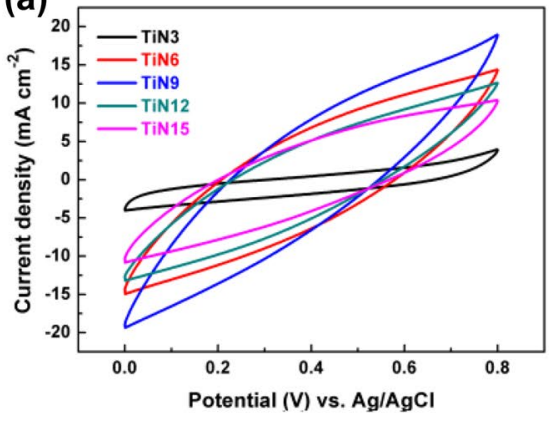

(b)

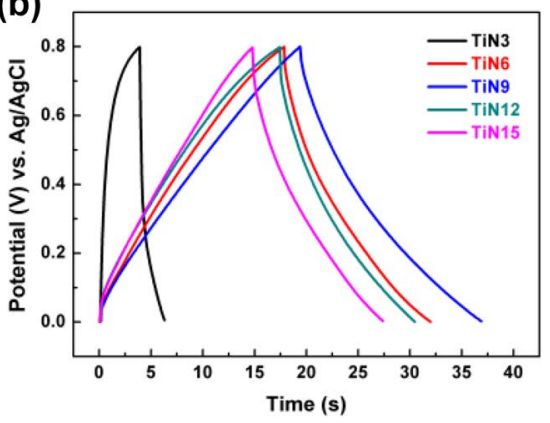

(c)

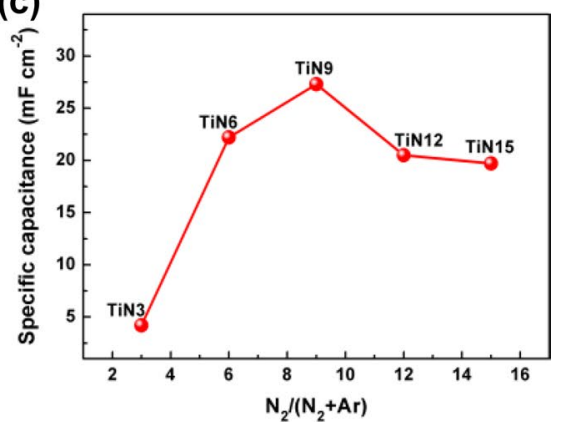

Fig. 4 Electrochemical performance of TiN thin film electrodes using a three-electrode system: a CV curves at a scan rate of $1 \mathrm{~V} \mathrm{~s}{ }^{-1}$, $\mathbf{b}$ GCD curves at a current of $1.0 \mathrm{~mA} \mathrm{~cm}{ }^{-2}$ and $\mathbf{c}$ Relationship of the specific capacitance with respect to $\mathrm{N}_{2}$ content

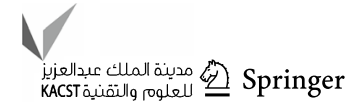


(a)

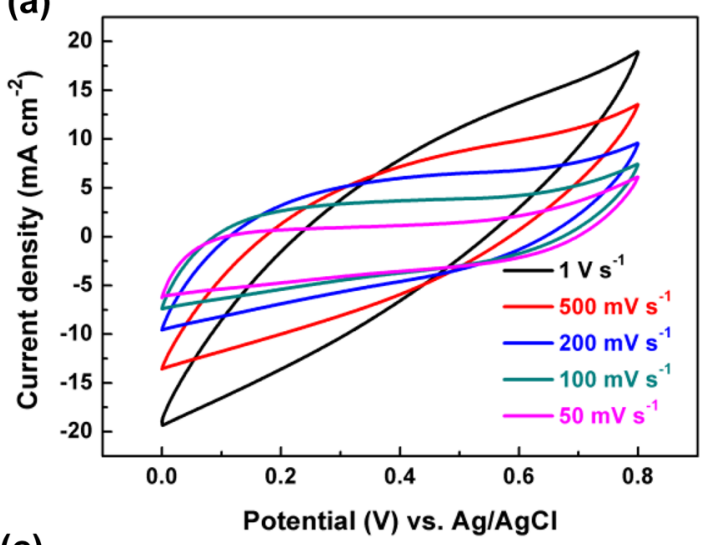

(c)

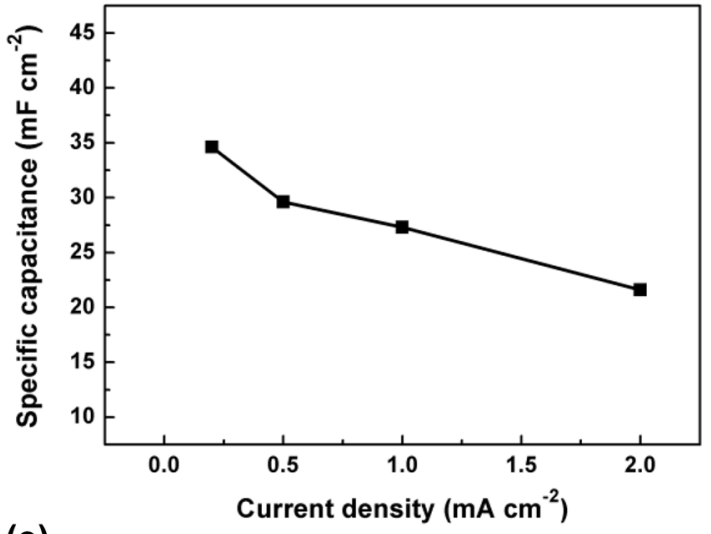

(e)

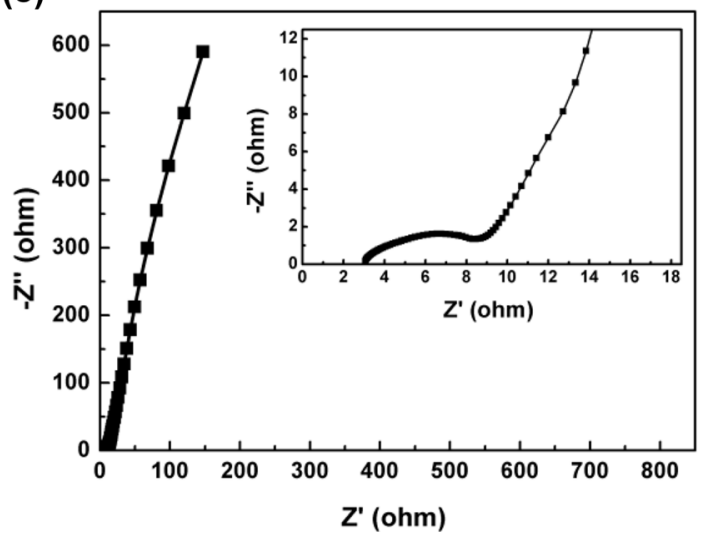

Fig. 5 Electrochemical performance of the TiN9 thin film electrode using a three-electrode system: a CV curves at different scan rates, b GCD curves at different current densities, c Comparison of specific capacitance versus current density, $\mathbf{d}$ Cycling stability as a function

(see inset of Fig. 5e), in concordance with GCD result. A good capacitor behavior can be corroborated due to the almost vertical line and nearly $90^{\circ}$ phase angle observed in the Bode plot (Fig. 5f). In addition, the characteristic frequency $\left(f_{0}\right)$ at $-45^{\circ}$ is around $0.87 \mathrm{~Hz}$, and thereby the time constant calculated by $1 / f_{0}$ equals $1.1 \mathrm{~s}$, depicting a fast energy release capability to ensure ultrahigh power and energy [37]. (b)

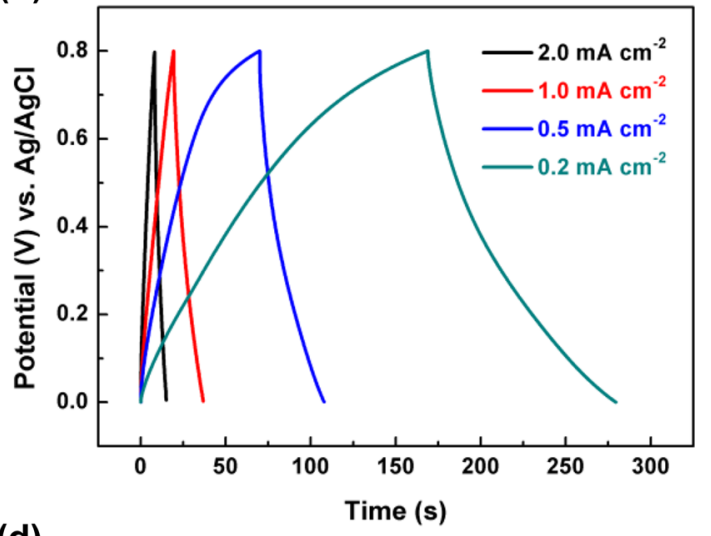

(d)

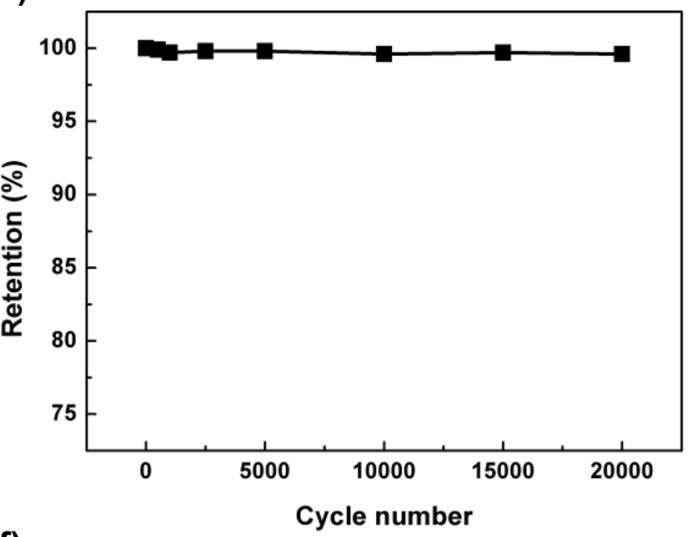

(f)

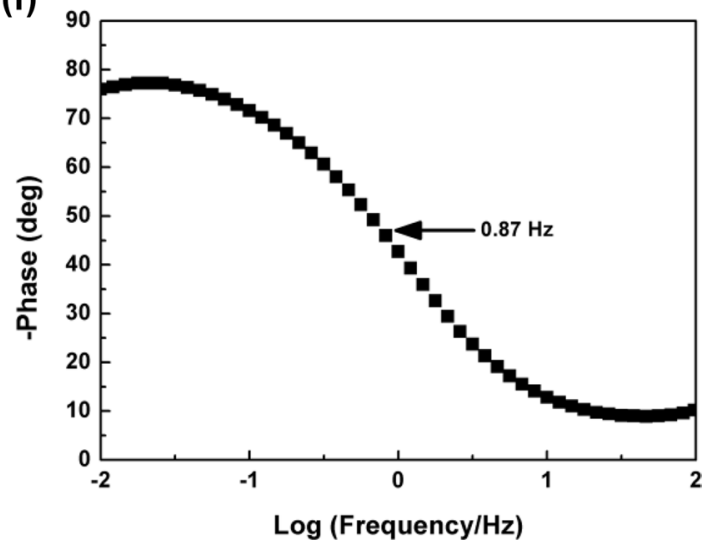

of cycle number at a current of $2.0 \mathrm{~mA} \mathrm{~cm}{ }^{-2}$, e Nyquist plot (the inset shows the enlarged Nyquist plot at the high-frequency region) and $\mathbf{f}$ Bode phase angle plot

To demonstrate the feasibility of TiN thin films as supercapacitor electrode materials, a symmetric supercapacitor device is fabricated using TiN thin films as both negative and positive electrodes. CV curves collected for TiN-based symmetric supercapacitor device at different scan rates are shown in Fig. 6a. These curves exhibit a mirror-image feature even at high scan rate up to $1 \mathrm{~V} \mathrm{~s}^{-1}$, indicating an ideal capacitor behavior. Figure $6 \mathrm{~b}$ shows 

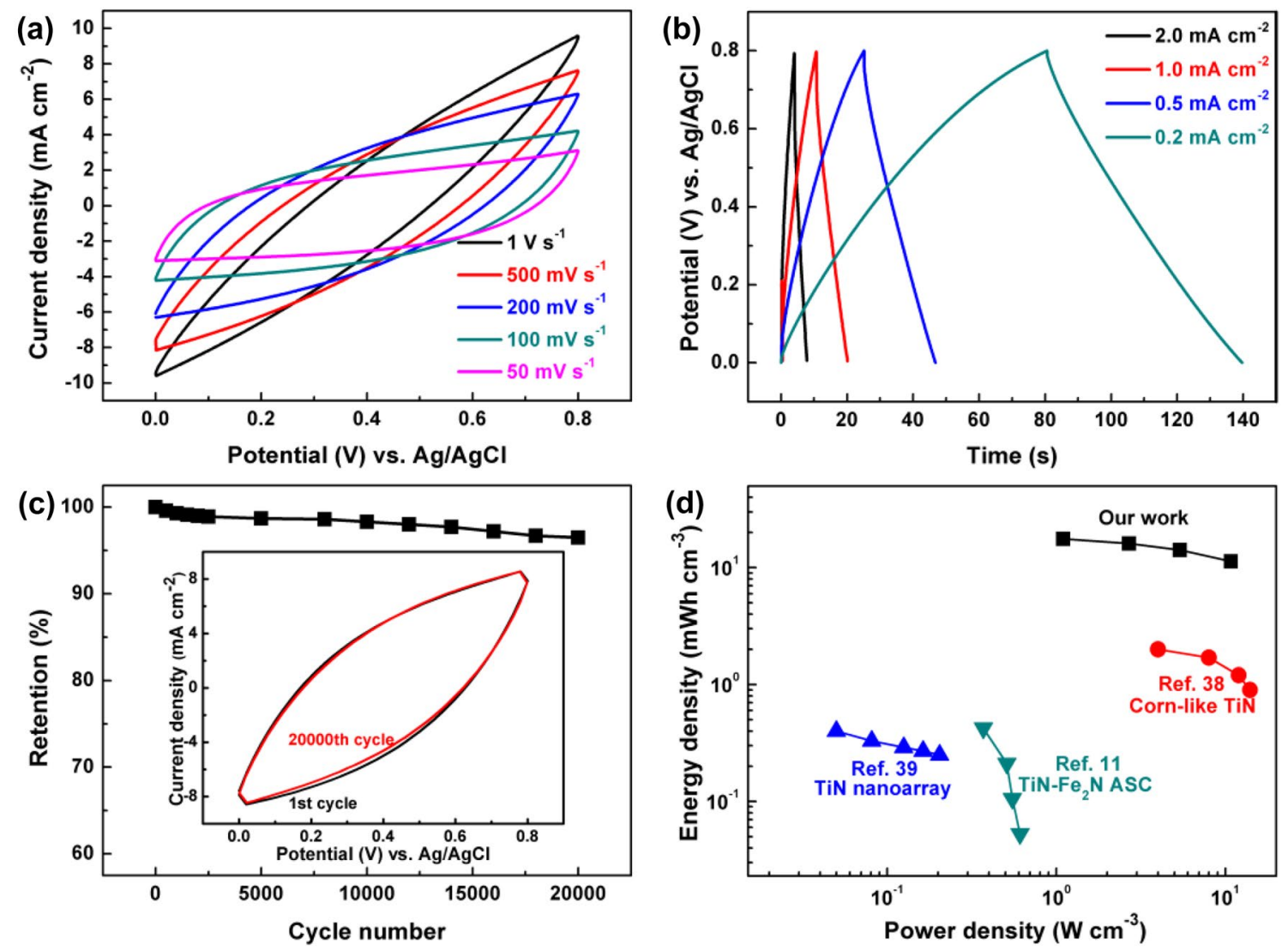

Fig. $6 \mathrm{TiN} / / \mathrm{TiN}$ symmetric supercapacitor performance: a CV curves at different scan rates, b GCD curves at different current densities, c Cycling stability at a current of $2.0 \mathrm{~mA} \mathrm{~cm}{ }^{-2}$ over 20,000 cycles

(the inset shows the CV curves of the 1st and 20000th cycles at $500 \mathrm{mV} \mathrm{s}^{-1}$ ) and d Ragone plot

the GCD curves of TiN-based symmetric supercapacitor device at various current densities. All the curves are almost symmetrical, independent of current density, confirming a high coulombic efficiency and good electrochemical property. The cycling stability of TiN-based symmetric supercapacitor device is evaluated at a current of $2.0 \mathrm{~mA} \mathrm{~cm}{ }^{-2}$ for 20,000 cycles. As shown in Fig. 6c, the specific capacitance of TiN-based symmetric supercapacitor device remains essentially unchanged over 20,000 cycles, indicative of an excellent cycling stability. Figure 6d compares the power and energy densities of TiN-based symmetric supercapacitor (Table S5) to other transition metal nitrides. A maximum energy density of $17.6 \mathrm{mWh} \mathrm{cm}^{-3}$ is achieved at a power density of $1.1 \mathrm{~W} \mathrm{~cm}^{-3}$ and this still retains $11.3 \mathrm{mWh} \mathrm{cm}^{-3}$ when the power density increases to $10.8 \mathrm{~W} \mathrm{~cm}^{-3}$, which is considerably higher than $\mathrm{TiN}-\mathrm{Fe}_{2} \mathrm{~N}$ ASC $\left(0.05 \mathrm{mWh} \mathrm{cm}^{-3}\right.$,

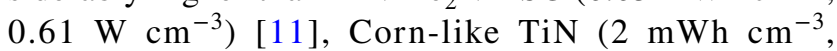
$\left.4 \mathrm{~W} \mathrm{~cm}^{-3}\right)$ [38] and TiN nanoarray $\left(0.4 \mathrm{mWh} \mathrm{cm}^{-3}\right.$, $0.05 \mathrm{~W} \mathrm{~cm}^{-3}$ ) [39].

\section{Conclusions}

In summary, we demonstrate the growth of TiN thin films on the silicon wafers using magnetron sputtering method under different nitrogen gas flow rates and investigate their electrochemical performance as supercapacitor electrodes. TiN thin film electrodes show long-term cycling performance with an optimized specific capacitance of $27.3 \mathrm{mF} \mathrm{cm}^{-2}$ at $1.0 \mathrm{~mA} \mathrm{~cm}{ }^{-2}$, which excels most of the previous transition metal nitrides. Furthermore, a symmetric supercapacitor device based on TiN thin films is successfully produced and achieves a maximum energy density of $17.6 \mathrm{mWh} \mathrm{cm}^{-3}$ at a power density of $1.1 \mathrm{~W} \mathrm{~cm}^{-3}$, along with outstanding cycling stability. These findings suggest that $\mathrm{TiN}$ thin films possess good application prospects in the field of supercapacitor.

Acknowledgements This research is financially supported by the National Nature Science Foundation of China (Nos. 51372212, 51601163). 


\section{Compliance with ethical standards}

\section{Conflict of interest There are no conflicts of interest.}

Open Access This article is distributed under the terms of the Creative Commons Attribution 4.0 International License (http://creativeco mmons.org/licenses/by/4.0/), which permits unrestricted use, distribution, and reproduction in any medium, provided you give appropriate credit to the original author(s) and the source, provide a link to the Creative Commons license, and indicate if changes were made.

\section{References}

1. Gao, G., Wu, H.B., Ding, S., Liu, L.M., Lou, X.W.: Hierarchical $\mathrm{NiCo}_{2} \mathrm{O}_{4}$ nanosheets grown on Ni nanofoam as high-performance electrodes for supercapacitors. Small 11, 804-808 (2015)

2. Lv, Q.Y., Wang, S., Sun, H.Y., Luo, J., Xiao, J., Xiao, J.W., Xiao, F., Wang, S.: Solid-state thin-film supercapacitors with ultrafast charge/discharge based on N-doped-carbon-tubes/Au-nanoparticles-doped- $\mathrm{MnO}_{2}$ nanocomposites. Nano Lett. 16, 40-47 (2015)

3. Zhao, X., Sánchez, B.M., Dobson, P.J., Grant, P.S.: The role of nanomaterials in redox-based supercapacitors for next generation energy storage devices. Nanoscale 3, 839-855 (2011)

4. Chen, Z., Qin, Y.C., Weng, D., Xiao, Q.F., Peng, Y.T., Wang, X.L., Li, H.X., Wei, F., Lu, Y.F.: Design and synthesis of hierarchical nanowire composites for electrochemical energy storage. Adv. Funct. Mater. 19, 3420-3426 (2009)

5. Huang, Y.L., Zeng, Y.X., Yu, M.H., Liu, P., Tong, Y.X., Cheng, F.L., Lu, X.H.: Recent smart methods for achieving high-energy asymmetric supercapacitors. Small Methods 2, 1700230 (2018)

6. Zeng, Y.X., Yu, M.H., Meng, Y., Fang, P.P., Lu, X.H., Tong, Y.X.: Iron-based supercapacitor electrodes: advances and challenges. Adv. Energy Mater. 6, 1601053 (2016)

7. Yu, M.H., Lin, D., Feng, H.B., Zeng, Y.X., Tong, Y.X., Lu, X.H.: Boosting the energy density of carbon-based aqueous supercapacitors by optimizing the surface charge. Angew. Chem. Int. Ed. 56, 5454-5459 (2017)

8. Xie, K., Qin, X.T., Wang, X.Z., Wang, Y.N., Tao, H.S., Wu, Q., Yang, L.J., Hu, Z.: Carbon nanocages as supercapacitor electrode materials. Adv. Mater. 24, 347-352 (2012)

9. Guan, C., Liu, J.P., Cheng, C.W., Li, H.X., Li, X.L., Zhou, W.W., Zhang, H., Fan, H.J.: Hybrid structure of cobalt monoxide nanowire@ nickel hydroxidenitrate nanoflake aligned on nickel foam for high-rate supercapacitor. Energy Environ. Sci. 4, 4496-4499 (2011)

10. Balogun, M.S., Qiu, W.T., Wang, W., Fang, P.P., Lu, X.H., Tong, Y.X.: Recent advances in metal nitrides as high-performance electrode materials for energy storage devices. J. Mater. Chem. A 3, 1364-1387 (2015)

11. Zhu, C.R., Yang, P.H., Chao, D.L., Wang, X.L., Zhang, X., Chen, S., Tay, B.K., Huang, H., Zhang, H., Mai, W.J., Fan, H.J.: All metal nitrides solid-state asymmetric supercapacitors. Adv. Mater. 27, 4566-4571 (2015)

12. Lu, X.H., Wang, G.M., Zhai, T., Yu, M.H., Xie, S.L., Ling, Y.C., Liang, C.L., Tong, Y.X., Li, Y.: Stabilized TiN nanowire arrays for high-performance and flexible supercapacitors. Nano Lett. 12, 5376-5381 (2012)

13. Sun, P., Lin, R., Wang, Z.L., Qiu, M.J., Chai, Z.S., Zhang, B.D., Meng, H., Tan, S.Z., Zhao, C.X., Mai, W.J.: Rational design of carbon shell endows TiN@C nanotube based fiber supercapacitors with significantly enhanced mechanical stability and electrochemical performance. Nano Energy 31, 432-440 (2017)
14. Tian, F., Xie, Y.B., Du, H.X., Zhou, Y.Z., Xia, C., Wang, W.: Preparation and electrochemical capacitance of graphene/titanium nitride nanotube array. Rsc Adv. 4, 41856-41863 (2014)

15. Achour, A., Porto, R.L., Soussou, M.A., Islam, M., Boujtita, M., Aissa, K.A., Brizoual, L.L., Djouadi, A., Brousse, T.: Titanium nitride films for micro-supercapacitors: effect of surface chemistry and film morphology on the capacitance. J. Power Sources 300, 525-532 (2015)

16. Wei, B.B., Liang, H.F., Zhang, D.F., Wu, Z.T., Qi, Z.B., Wang, Z.C.: $\mathrm{CrN}$ thin films prepared by reactive DC magnetron sputtering for symmetric supercapacitors. J. Mater. Chem. A 5, 2844-2851 (2017)

17. Xia, F.F., Wu, M.H., Wang, F., Jia, Z.Y., Wang, A.L.: Nanocomposite Ni-TiN coatings prepared by ultrasonic electrodeposition. Curr. Appl. Phys. 9, 44-47 (2009)

18. Piumetti, M., Bensaid, S., Russo, N., Fino, D.: Nanostructured ceria-based catalysts for soot combustion: investigations on the surface sensitivity. Appl. Catal. B 165, 742-751 (2015)

19. Saoula, N., Djerourou, S., Yahiaoui, K., Henda, K., Kesri, R., Erasmus, R.M., Comins, J.D.: Study of the deposition of Ti/TiN multilayers by magnetron sputtering. Surf. Interface Anal. $\mathbf{4 2}$, 1176-1179 (2010)

20. Ding, Z.H., Yao, B., Qiu, L.X., Lv, T.Q.: Raman scattering investigation of nanocrystalline $\delta$-TiN $\mathrm{T}_{\mathrm{x}}$ synthesized by solidstate reaction. J. Alloys Compd. 421, 247-251 (2006)

21. $\mathrm{Wu}, \mathrm{M} . \mathrm{N}$.: Low temperature synthesis of nanocrystalline titanium nitride from a single-source precursor of titanium and nitrogen. J. Alloys Compd. 486, 223-226 (2009)

22. Wang, Y., Yuan, H.Y., Lu, X.L., Zhou, Z.D., Xiao, D.: All solidstate $\mathrm{pH}$ electrode based on titanium nitride sensitive film. Electroanalysis 18, 1493-1498 (2006)

23. Yang, S.D., Chen, L., Mu, L., Hao, B., Chen, J.T., Ma, P.C.: Graphene foam with hierarchical structures for the removal of organic pollutants from water. RSC Adv. 6, 4889-4898 (2016)

24. Wu, Z.T., Qi, Z.B., Zhang, D.F., Wei, B.B., Wang, Z.C.: Evaluating the influence of adding $\mathrm{Nb}$ on microstructure, hardness and oxidation resistance of $\mathrm{CrN}$ coating. Surf. Coat. Technol. 289, 45-51 (2016)

25. Han, Z.H., Tian, J.W., Lai, Q.X., Yu, X.J., Li, G.Y.: Effect of $\mathrm{N}_{2}$ partial pressure on the microstructure and mechanical properties of magnetron sputtered $\mathrm{CrN}_{\mathrm{x}}$ films. Surf. Coat. Technol. 162, 189-193 (2003)

26. Wuhrer, R., Kim, S., Yeung, W.Y.: Effect of nitrogen partial pressure on the surface morphology and properties of reactive dc magnetron sputtered ( $\mathrm{Ti}, \mathrm{Al}) \mathrm{N}$ coatings. Scr. Mater. 37, 1163-1169 (1997)

27. Liu, Q., Liu, Y., Zhu, X.R., Hu, M.: Influence of $\mathrm{Ar}$ and $\mathrm{N}_{2}$ flow ratio on TiN thin films prepared by magnetron sputtering. Mater. Mech. Eng. 33, 8-11 (2009)

28. Cui, H.L., Zhu, G.L., Liu, X.Y., Liu, F.X., Xie, Y., Yang, C.Y., Lin, T.Q., Gu, H., Huang, F.Q.: Niobium nitride $\mathrm{Nb}_{4} \mathrm{~N}_{5}$ as a new high-performance electrode material for supercapacitors. Adv. Sci. 2, 1500126 (2015)

29. Zhao, Y., Hu, L.F., Zhao, S.Y., Wu, L.M.: Preparation of $\mathrm{MnCo}_{2} \mathrm{O}_{4} @ \mathrm{Ni}(\mathrm{OH})_{2}$ core-shell flowers for asymmetric supercapacitor materials with ultrahigh specific capacitance. Adv. Funct. Mater. 26, 4085-4093 (2016)

30. Zhang, D.S., Wen, X.R., Shi, L.Y., Yan, T.T., Zhang, J.P.: Enhanced capacitive deionization of graphene/mesoporous carbon composites. Nanoscale 4, 5440-5446 (2012)

31. Luo, Y.Z., Zhang, H.M., Wang, L., Zhang, M., Wang, T.H.: Fixing graphene- $\mathrm{Mn}_{3} \mathrm{O}_{4}$ nanosheets on carbon cloth by a poles repel-assisted method to prepare flexible binder-free electrodes for supercapacitors. Electrochim. Acta 180, 983-989 (2015)

32. Zhang, J.T., Jiang, J.W., Li, H.L., Zhao, X.S.: A highperformance asymmetric supercapacitor fabricated with 
graphene-based electrodes. Energy Environ. Sci. 4, 4009-4015 (2011)

33. An, K.H., Kim, W.S., Park, Y.S., Moon, J.M., Bae, D.J., Lim, S.C., Lee, Y.S., Lee, Y.H.: Electrochemical properties of highpower supercapacitors using single-walled carbon nanotube electrodes. Adv. Funct. Mater. 11, 387-392 (2001)

34. Lu, P., Ohlckers, P., Müller, L., Leopold, S., Hoffmann, M., Grigoras, K., Ahopelto, J., Prunnila, M., Chen, X.Y.: Nano fabricated silicon nanorod array with titanium nitride coating for on-chip supercapacitors. Electrochem. Commun. 70, 51-55 (2016)

35. Wang, L., Ji, H.M., Wang, S.S., Kong, L.J., Jiang, X.F., Yang, G.: Preparation of $\mathrm{Fe}_{3} \mathrm{O}_{4}$ with high specific surface area and improved capacitance as a supercapacitor. Nanoscale 5, 3793-3799 (2013)

36. Xie, Y.B., Tian, F.: Capacitive performance of molybdenum nitride/titanium nitride nanotube array for supercapacitor. Mater. Sci. Eng., B 215, 64-70 (2017)
37. Wu, Z.S., Parvez, K., Feng, X.L., Müllen, K.: Graphene-based in-plane micro-supercapacitors with high power and energy densities. Nat. Commun. 4, 2487 (2013)

38. Yang, P.H., Chao, D.L., Zhu, C.R., Xia, X.H., Zhang, Y.Q., Wang, X.L., Sun, P., Tay, B.K., Shen, Z.X., Mai, W.J., Fan, H.J.: Ultrafast-charging supercapacitors based on corn-like titanium nitride nanostructures. Adv. Sci. 3, 1500299 (2015)

39. Xie, Y.B., Wang, Y., Du, H.X.: Electrochemical capacitance performance of titanium nitride nanoarray. Mater. Sci. Eng., B 178, 1443-1451 (2013)

Publisher's Note Springer Nature remains neutral with regard to jurisdictional claims in published maps and institutional affiliations. 